\title{
Propargyl bromide as an excellent $\alpha$-Bromoacetone equivalent: Convenient and New route to $\alpha$-aroylacetones
}

\author{
Sakkarapalayam. M. Mahalingam, Indrapal Singh Aidhen ${ }^{*}$ \\ Department of Chemistry, Indian Institute of Technology Madras, Chennai - 600 036, \\ India \\ E-mail: isingh@iitm.ac.in \\ Supporting information \\ Table of Contents
}

[A] Experimental section

[B] ${ }^{1} \mathrm{H}$ NMR, ${ }^{13} \mathrm{C}$ NMR spectra

(i) Compound $1 \mathrm{~g}$

S3-S4

(ii) Compound 3a

S5

(iii) Compound $\mathbf{3 b}$

S6

(iv) Compound 4a

S7

(v) Compound $\mathbf{4 b}$

S8

(vi) Compound 4e

S9

[C] High Resolution Mass spectra

$\begin{array}{ll}\text { (i) Compound 3a } & \mathrm{S} 10\end{array}$

(ii) Compound 4b $\quad \mathrm{S} 10$

$\begin{array}{ll}\text { (iii) Compound 4e } & \mathrm{S} 11\end{array}$

[D] DEPT spectrum of $\mathbf{4 a} \quad \mathrm{S} 11$ 


\title{
General Methods and Materials
}

\begin{abstract}
All solvents were distilled before use. Anhydrous DMF prepared using standard procedure involving drying over $\mathrm{CaH}_{2}$ and distillation under reduced pressure. Melting points were determined in capillary and are uncorrected. ${ }^{1} \mathrm{H}$ NMR $(400 \mathrm{MHz})$ and ${ }^{13} \mathrm{C}$ NMR (100 MHz) spectra were recorded using deuteriochloroform $\left(\mathrm{CDCl}_{3}\right)$ as solvent and tetramethylsilane (TMS) as a reference. IR spectra were recorded using $\mathrm{KBr}$ pallet for solid samples and neat for liquid samples. Electron-Impact mass spectra and HRMS were accomplished at $70 \mathrm{eV}$. All the reactions were monitored by TLC on precoated silica-gel plates by developing the spots with iodine vapors or under UV-light absorbance.
\end{abstract}


틈

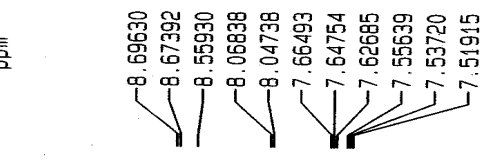
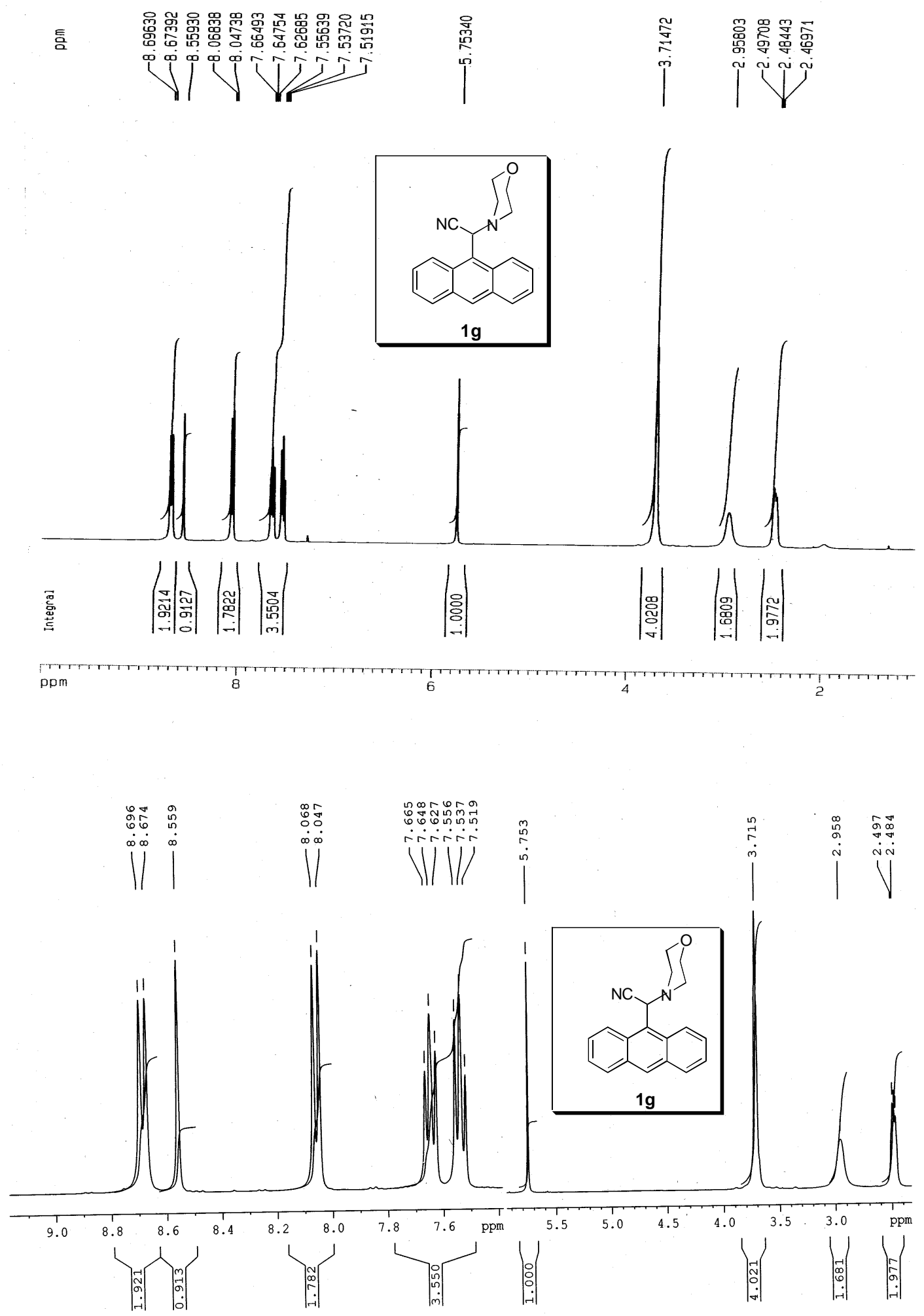


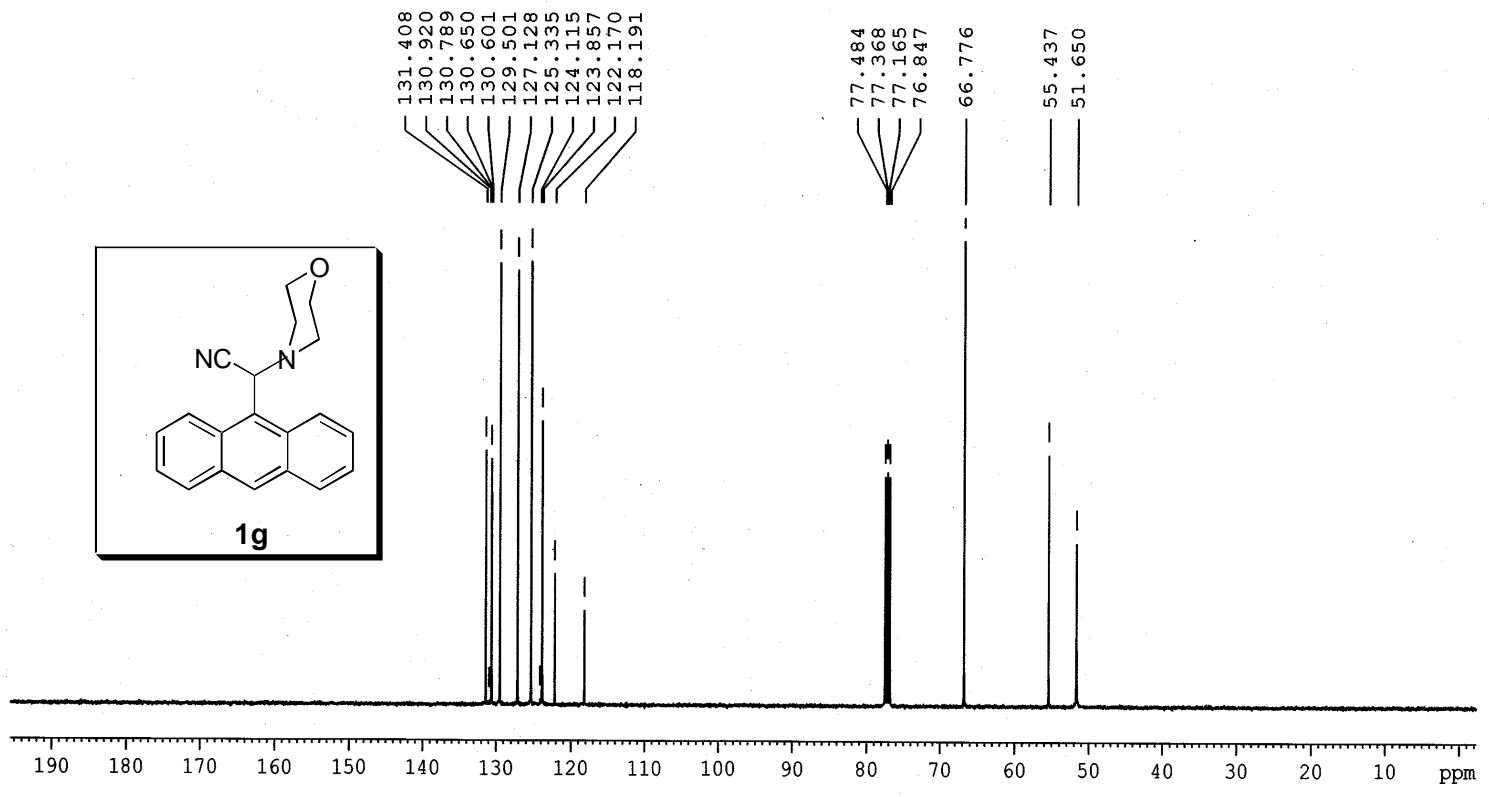



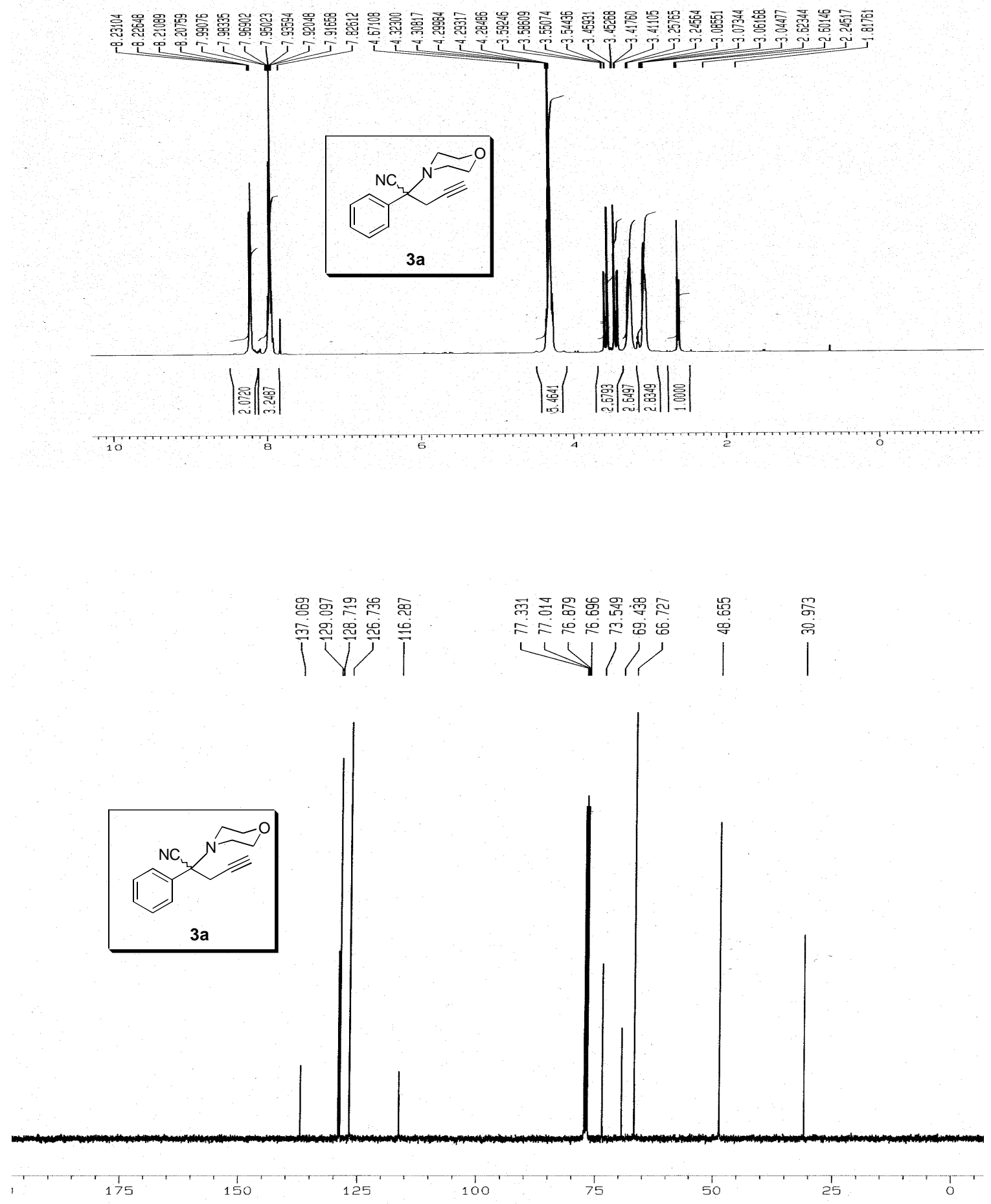


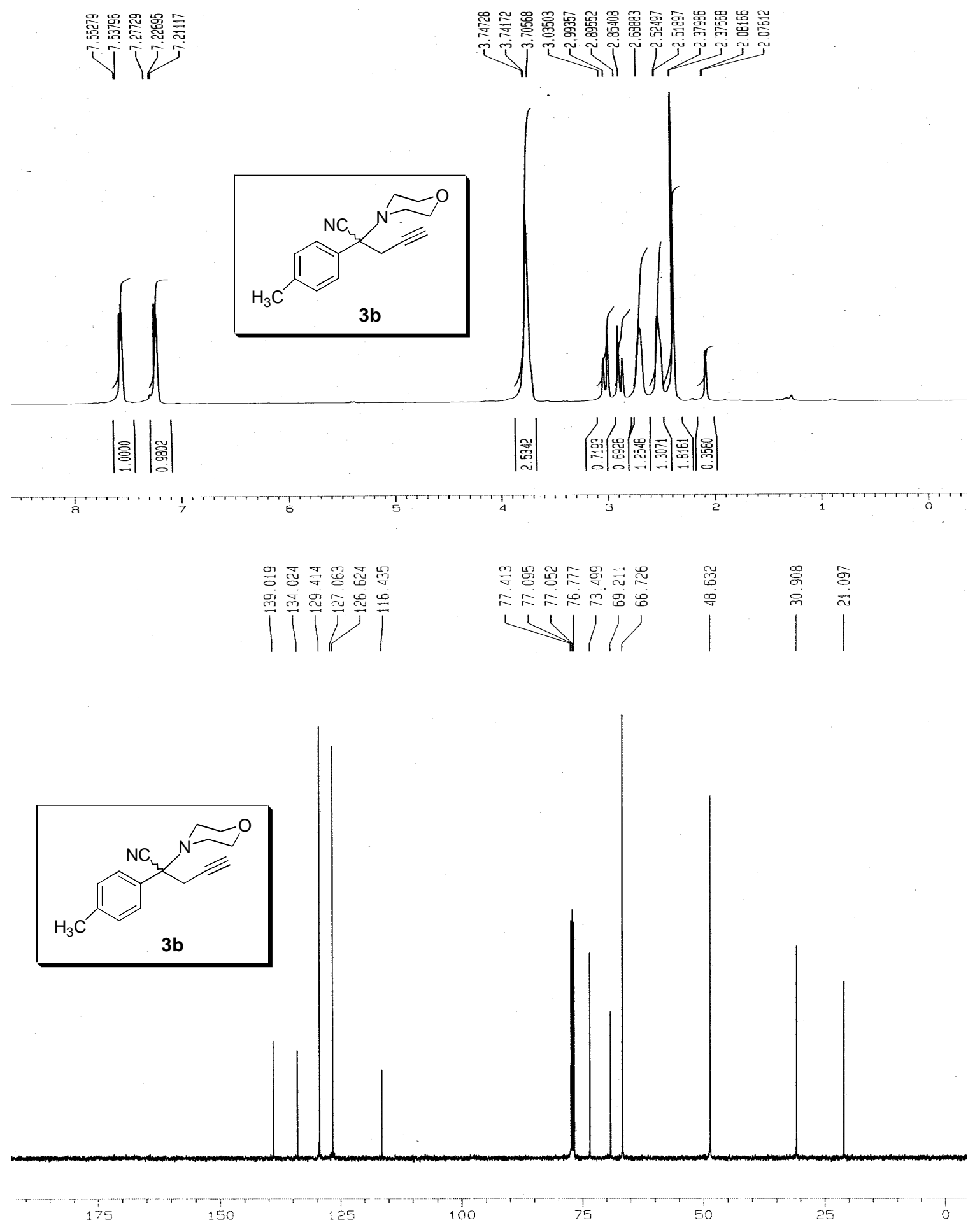



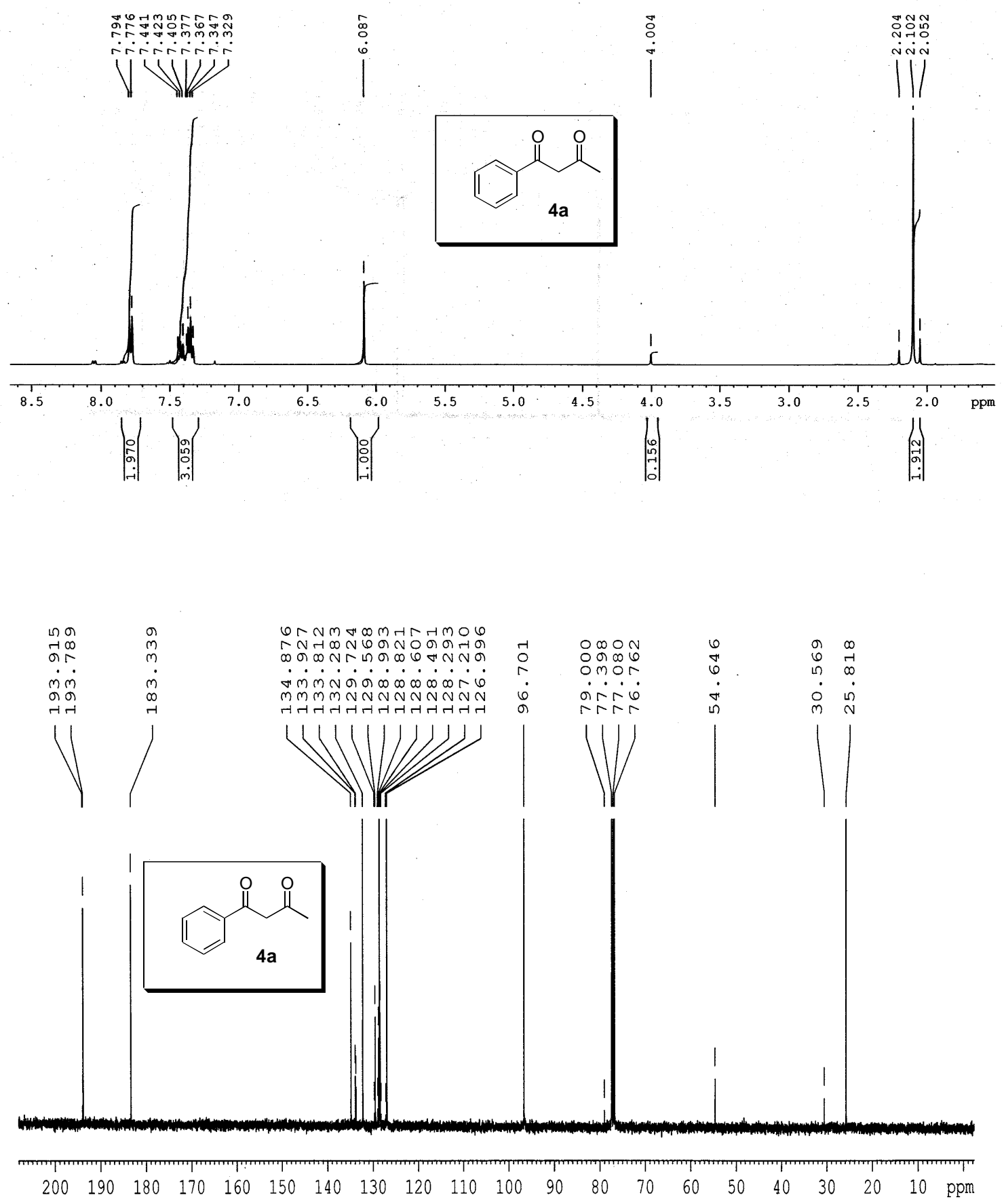

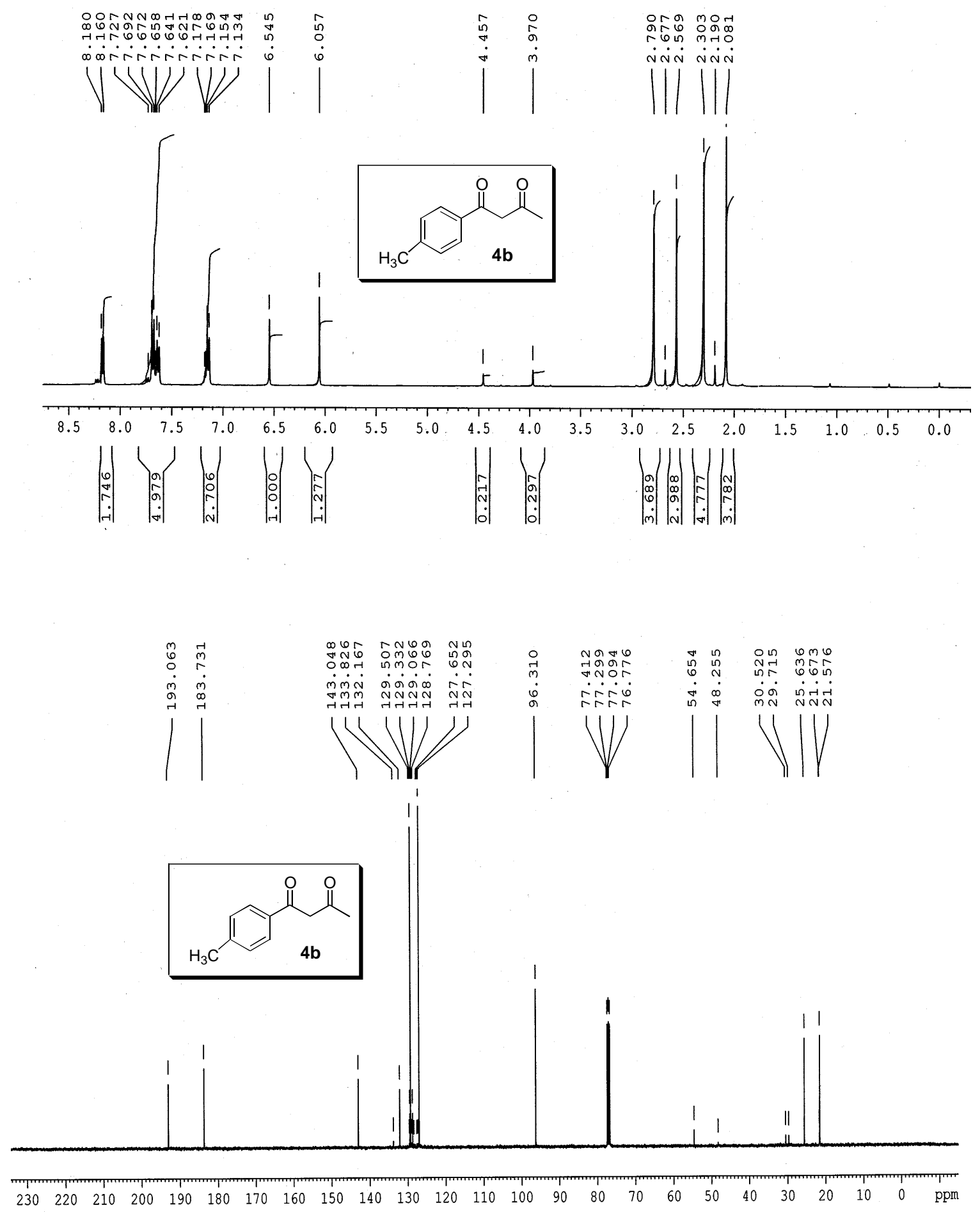

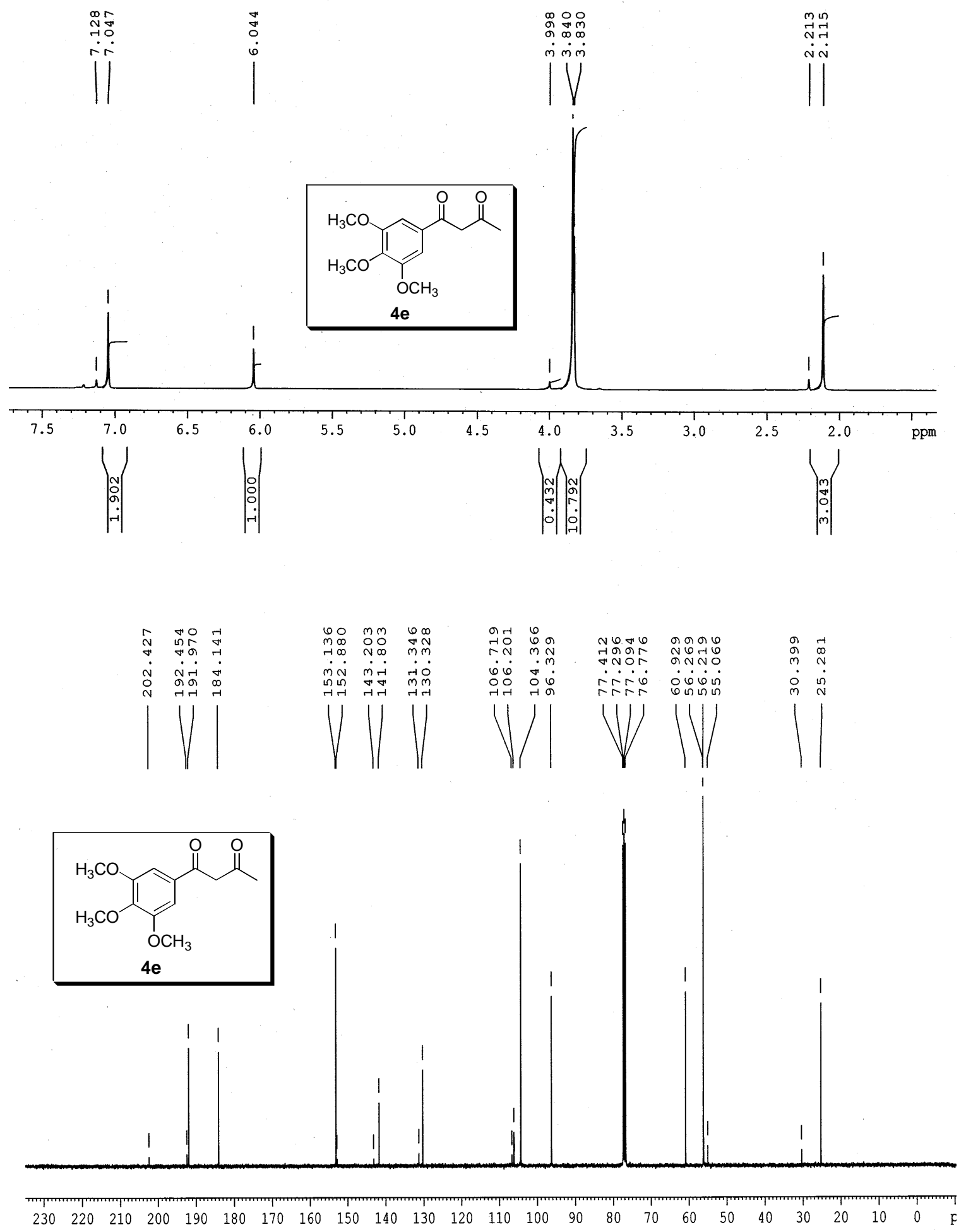


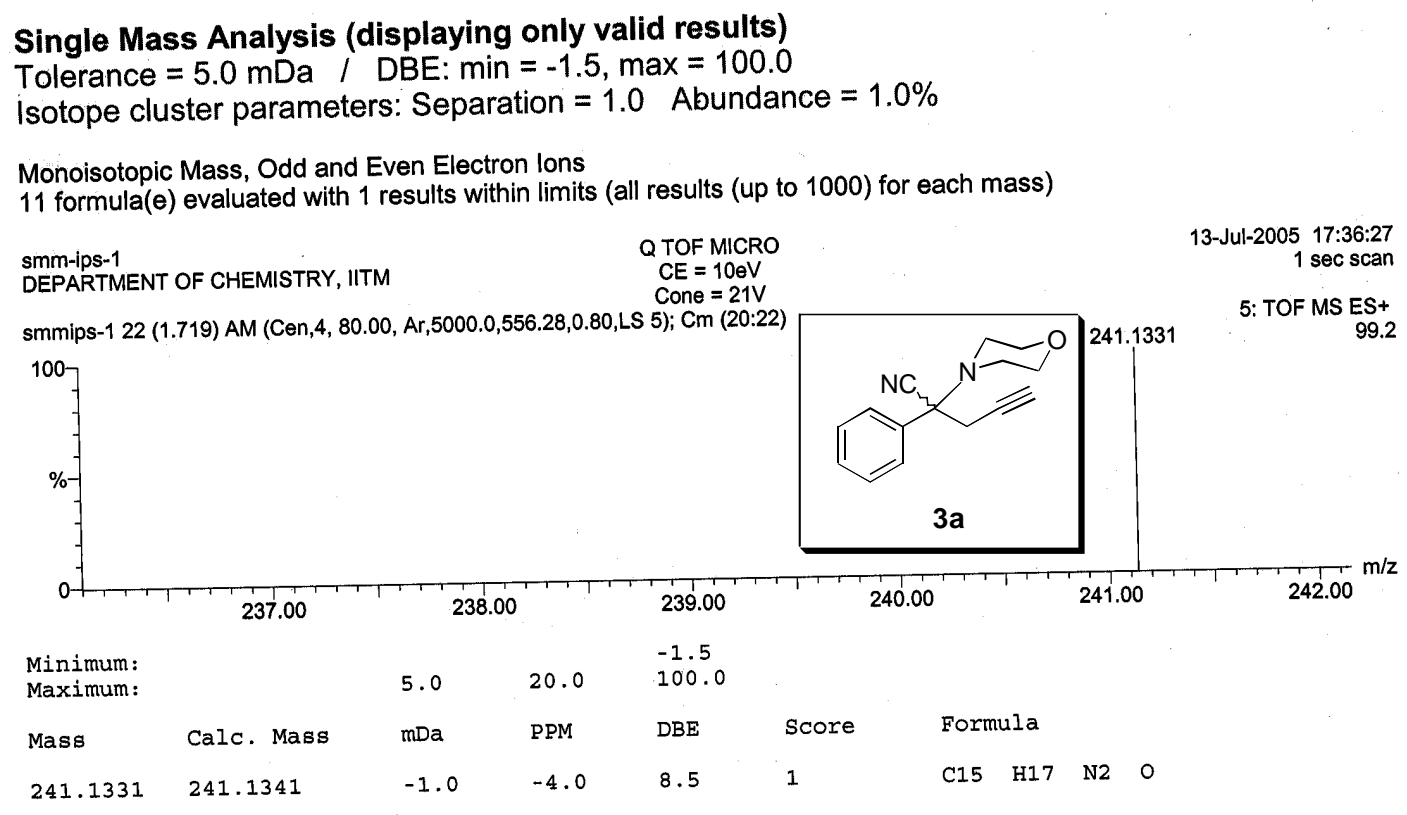

Elemental Composition Report

Page 1

Single Mass Analysis (displaying only valid results)

Tolerance $=5.0 \mathrm{mDa} / \mathrm{DBE}: \min =-1.5, \max =100.0$

Isotope cluster parameters: Separation $=1.0$ Abundance $=1.0 \%$

Monoisotopic Mass, Odd and Even Electron lons

10 formula(e) evaluated with 1 results within limits (all results (up to 1000) for each mass)

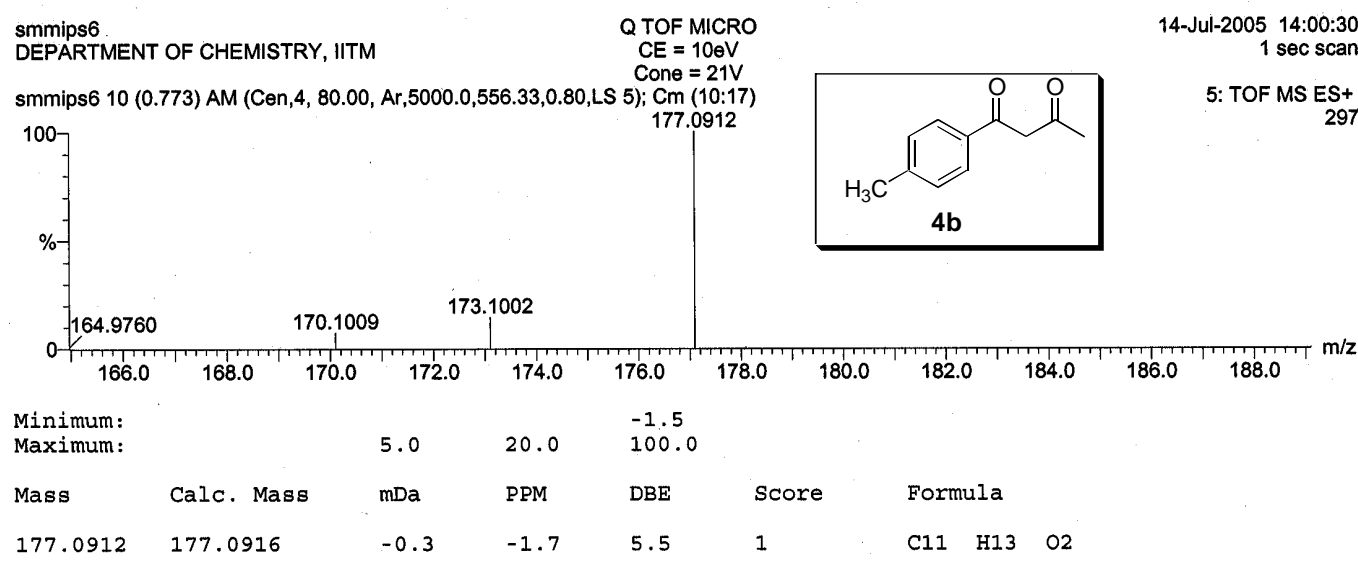




\section{Elemental Composition Report}

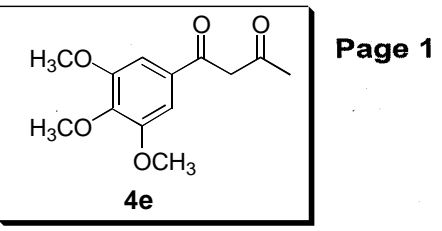

Single Mass Analysis (displaying only valid results)

Isotope cluster parameters: Separation $=1.0$ Abundance $=1.0 \%$

$4 \mathrm{e}$

Monoisotopic Mass, Odd and Even Electron lons

5 formula(e) evaluated with 1 results within limits (all results (up to 1000) for each mass)
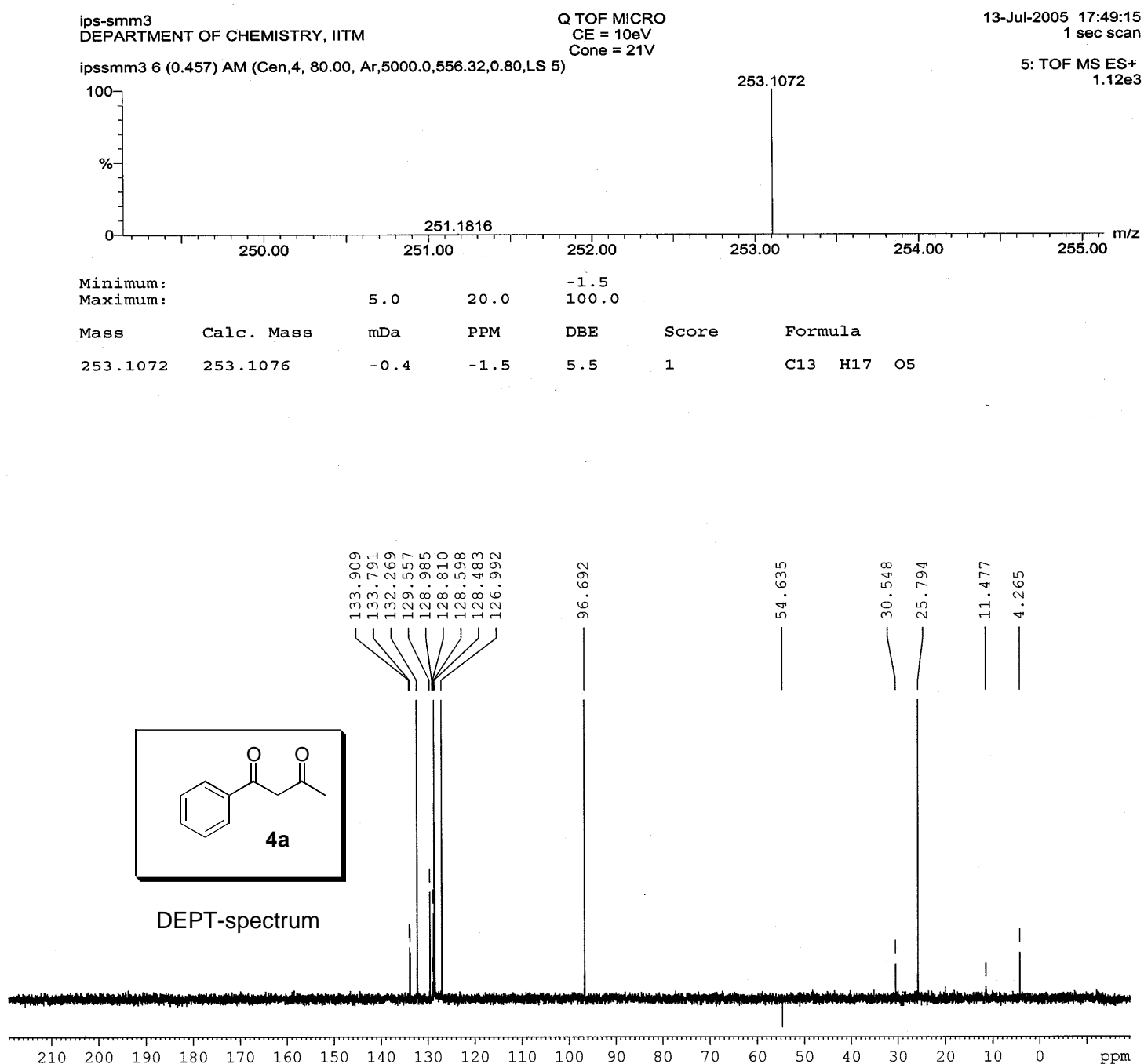